\title{
MJN A VALIDATION OF A NON-LINEAR RELATIONSHIP ON THE PREDICTORS OF VIOLENCE AGAINST WOMEN (VAW) BY SYMBOLIC REGRESSION
}

\author{
Lovelyn Garcia-tipon*, Ernyl Henry E. Redula \\ Cebu Normal University, Philippines \\ *Corresponding Author s Email: lovelyngtipon@gmail.com
}

\begin{abstract}
Violence against women is a global public health problem that has serious adverse effects on women's physical, mental, and reproductive health. It is increasingly recognized as a public health issue because of the expanding evidence based on the growth of research documenting owing to its magnitude and health effects on women despite the government's effort of eradicating this societal dilemma. Utilizing the symbolic regression, the researcher was able to determine the non-linear relationship of the variables (physical injury and rape case) in the total incidence rate of violence against women across the globe. It also shows which among the predictors greatly affect the high incidence rate of violence to its total number of violence. The effects of violence changes as the number of violence are varied because physical injury may no longer mean a direct impact to the lives of women nowadays, but rather some would only consider it as part of their daily lives or behavior. However, increasing the number of physical injuries increases the rate of violence against women. The decrease in the trend indicates an inverse relation of the two variables which would mean that rape cases are not considered as part of the emerging violence against women. There is a positive and direct relationship among the variables. Physical injury affects the rate of violence. However, both physical injury and rape cases incidence serves as the most common contributory factors regarding why the competence of women in the society has been greatly affected.
\end{abstract}

Keyword: Violence, Women, Physical Injury, Rape, Symbolic Regression

\section{INTRODUCTION}

Women and child violence is a global public health problem that has serious adverse effects on women's physical, mental and reproductive health. It is increasingly recognized as a public health dilemma because of the expanding evidence base and growth of research documenting its severity and health effects on women. According to the World Health Organization dated 2017, for the first time, global prevalence estimates have been calculated based on all existing data from population-based studies showing that worldwide, $35 \%$ of women have experienced either physical and/or sexual violence in their lifetime. "Multi-sectoral efforts are needed to combat this deeprooted problem. In fact, in the Philippines this problem is very rampant, that it is why the government has established various laws and regulations in order to minimize if not eradicate this societal domestic problem among old and young Filipinas. Violence against women is an obstacle to the achievement of the objectives of equality, development and peace. Both these factors violate and impair or nullifies what women deserve regarding their human rights and fundamental freedoms" (Women, Statistics on violence against Filipino women, 2014). Violence against women throughout their life cycle is a manifestation of the historically unequal power relations between women and men. It is perpetuated by traditional and customary practices that accord women lower status in the family, workplace, community and society, and it is exacerbated by social pressures. Images of violence in the media against women especially those that depict rape, sexual slavery or the use of women and girls as sex objects, including pornography are factors contributing to the continued prevalence of such violence, adversely 
influencing the community at large, in particular children and young people.

There are various forms of abuse that causes violence against women in the world which includes domestic violence, sexual abuse, sexual harassment, psychological violence, sexual exploitation, sexual trafficking, female genital mutilation, femicide, dowryrelated abuse, and acid-throwing (Bernarte et al., 2018). The sexual act like rape and physical violence that plagues many women as adults is also very much prevalent among female children, particularly adolescents.

Due to these unremarkable events in women's life the authors would like to capture the extent and types of violence experienced by women all throughout the globe.

\section{LITERATURE REVIEW}

In surveys that examine women's experiences during the reproductive period typically ages 15 to 49 years the annual prevalence of physical and sexual violence by intimate partners generally decreases with age with the highest rates being experienced by those between 15 to 19 years of age. This suggests a greater vulnerability to violence among younger females who are either still children, according to international definitions, or who have just emerged from childhood. In violence against children surveys in Kenya, Swaziland and Tanzania almost half of its women experienced sexual violence as a child, primarily at the hands of dating partners or men and boys from their neighbourhood. These and other surveys in low- and middle-income countries also suggest that physical violence is even more common, with six to eight out of ten girls are physically abused. Boys also experience such violence at the hands of parents, other caregivers, and teachers. Female children all over the world start experiencing sexual and physical violence at the hands of boys and men they know well before they become adults. These experiences may have damaging impacts on their mental and physical health. Moreover, they might in as well as their likelihood of continuing to experience such violence till adulthood.

Globally, at least one in every three woman has been beaten, coerced into sex, or otherwise abused in her lifetime. "Most often the abuser is a member of her own family. Increasingly, gender-based violence is recognized as a major public health concern and a violation of human rights. It has been reported that worldwide, one of the most common forms of violence against women is abuse by their husbands or other intimate male partners. Violence from partner occurs in all countries and transcends socially, economically, religiously, and within cultural groups. Although existence of violence and abuse from women can occur in some same-sex relationships, the vast majority of partner abuse is perpetrated by men against their female partners (Heise \& Ellsberg, 1999). Based on a report from the Philippine Commission on Women last 2009, women violence is deemed to be closely related to the unequal power relationship between women and men otherwise known as "gender based violence." The Society's norms and traditions seems to dictate that people should think that men are the leaders, pursuers, providers, and take on dominant roles in society while women are nurturers, men's companions and supporters, and take on subordinate roles in society especially in the family. These traditional views lead to men gaining more power over women. With power comes the need to control or to retain that power. And women violence becomes its form of men's expression of controlling women to retain power (Women, Violence Againts Women, 2009). Sandvik et al., (2017) stated in her study that "most of these offenders are young and their understanding of mutuality in the relationship with their victim mostly contributed to the sexual offence. Furthermore, moral immaturity, learning difficulties or being a refugee, exposure to child pornography, impulsivity and high sexual arousal were described as having impacted on their offending. According to Heise \& Ellsberg, (1999) most abused women are not passive victims but rather they use active strategies to maximize their safety and that of their children. Some women resist, others flee, and still others attempt to keep the peace by capitulating to their husbands' demands. What may seem to an observer to be lack of response to living with violence may in fact be strategic assessment of what it takes for the woman to survive in the marriage and to protect herself and her children. A woman's response to abuse is often limited by the options available to her. Women consistently cite similar reasons that they remain in an abusive relationships: fear of retribution, lack of other means of economic support, concern for the children, emotional dependence, lack of support from family and friends, and an abiding hope that "he will change." 


\section{CONCEPTUAL FRAMEWORK}

Violence is experienced by women of all ages and social classes, all races, religions and nationalities, all over the world. It is overwhelmingly perpetrated by men offenders. Violence against Women in the family or domestic violence is "violence that occurs within the private sphere, generally between individuals who are related through intimacy, blood or law." It may take the form of physical violence or sexual violence.

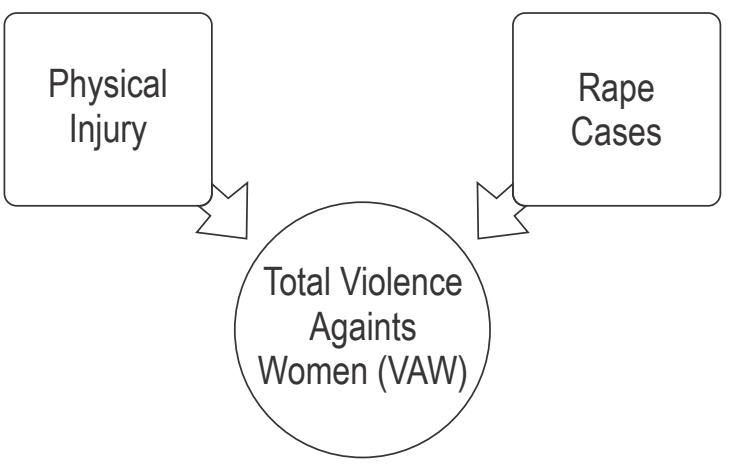

Figure 1: Framework on the relationship of the predictors of $V A W$ to its total incidence

In the present study, figure 1 shows the framework on the relationship of the predictors of violence against women (VAW) to its total incidence rate. The independent variable in this study is the total number of violence experienced by women while the dependent variables which are considered as the predictors of this study includes the incidence rate on physical injury and rape cases. Physical violence is exercised through physically aggressive acts such as hitting with the fist, slapping, kicking different parts of the body, stabbing with a knife, biting, beating or even strangling. Intentionally inflicted injuries are often disguised as accidents. At times, women are seriously injured and, in some cases, die as a result of their injuries. Findings from a number of recent studies from various parts of the world show that between $10 \%$ and $60 \%$ of the women had been hit or otherwise physically assaulted by an intimate male partner at some point in their lives. About $3 \%$ to $52 \%$ of the women reported physical violence in the previous year (Krantz \& GarciaMoreno, 2005).

On the other hand, Sexual violence on women such as rape, sexual harassment, acts of lasciviousness, treating a woman or child as a sex object, making demeaning and sexually suggestive remarks, physically attacking the sexual parts of the victim's body, forcing her to watch obscene publications and indecent shows or forcing the woman or her child to do indecent acts and/or make films thereof, and even forcing the wife and mistress/lover to live in the conjugal home or sleep together in the same room with the abuser. Both variables play a role in the increasing incidence rate of violence against women. Either physically or sexually abuse both will have damaging effect in the women's physical and mental well being.

\section{RESEARCH METHODOLOGY}

The researchers utilized the symbolic regression. A type of regression analysis that searches the space of mathematical expressions to find the model that best fits a given data set both in terms of accuracy and simplicity. Through the process of Data Mining, the researcher extracted the data on the predictors affecting the extent and type of violence experienced by women across the globe. The base action in the study is the total number of violence( $\mathrm{Y})$ accounted among women associated with its variables on the number of physical injury (X1) and the total number of rape cases (X2) reported both among women. The data searched of the various predictors were computed for mathematical expressions of accurate prediction equation for structural relationship of the data.

\section{RESULTSAND DISCUSSION}

Issue 1. Does the incidence of physical injuries among women affect its total women violence prevalence rate?

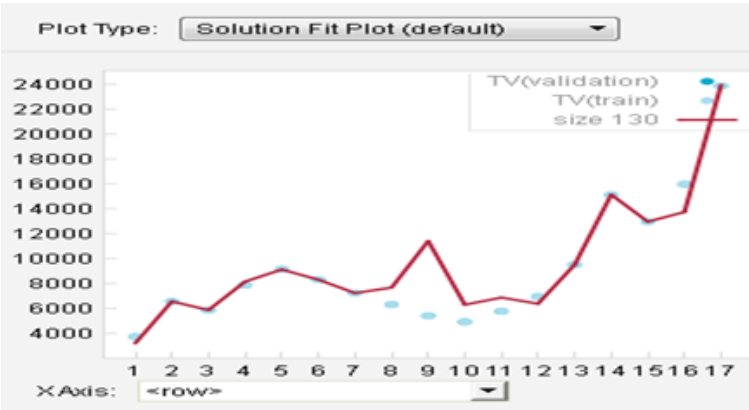

Figure 2: The relationship of physical injury rate to the total violence rate against women Formula:

$T V=9.36+3.28 e 3 \cos (0.988 P I)$

$$
\begin{aligned}
& +\frac{-69.7}{\sin (0.562+P I)}+1.4 e 4 \sin (0.562 P I) \cos (0.968 P I) \\
& +1.17 e 4 \cos (0.988 P I) \cos (0.968 P I) \cos (P I+\cos (0.988 P I))
\end{aligned}
$$




\begin{tabular}{|l|l|}
\hline Solution & Solution"TV=9360.14167528049+3282.53110023445* \\
& $\cos \left(0.987956735306654^{*} \mathrm{PI}\right)+69.7484016450274 / \sin ($ \\
& $0.562053431337544+\mathrm{PI})+11441.8415151564^{*} \sin (0.56$ \\
& $2053431337544+\mathrm{PI})^{*} \cos \left(0.968036353662242^{*} \mathrm{PI}\right)+11$ \\
& $687.4819443273^{*} \cos \left(0.987956735306654^{*} \mathrm{PI}\right)^{*} \cos (0$. \\
& $\left.968067281501182^{*} \mathrm{PI}\right)^{*} \cos (\mathrm{PI}+\cos (0.9879567353066$ \\
& $\left.\left.54^{*} \mathrm{PI}\right)\right)^{"}$ \\
\hline "R² Goodness of Fit" & 0.88962045 \\
\hline Correlation Coefficient" & 0.94668025 \\
\hline "Maximum Error" & 6010.8118 \\
\hline "Mean Squared Error" & 2756745.1 \\
\hline "Mean Absolute Error" & 803.2458 \\
\hline Coefficients & 12 \\
\hline Complexity & 130 \\
\hline Primary objective & 803.2458 \\
\hline "Fit (Normalized Primary & 0.23777497 \\
\hline Obj.)" & \\
\hline
\end{tabular}

Solution details (Calculated on validated data)

The relationship of physical injury rate to the total violence rate against women is shown in Figure 2 graph. The data shows a trigonometric fit trend (see equation $1)$. The $R^{2}$ is close to 1 indicating a reasonably good model fit and it shows a strong correlation between $\mathrm{x}$ and $\mathrm{y}$ variables. Fluctuations in the graph indicate a nonlinear relationship. Increasing the incidents of physical injury does not account for a constant increase in the number of violence against women. In nearly 50 population-based surveys from around the world, 10\% to over $50 \%$ of women report being hit or otherwise physically harmed by an intimate male partner at some point in their lives. Most women who suffer any physical aggression generally experience multiple acts over time. In the Leon study, for example, $60 \%$ of women abused in the previous year were abused more than once, and $20 \%$ experienced severe violence more than six times. Among women reporting any physical aggression, 70\% reported severe abuse. The average number of physical assaults in the previous year among currently abused women surveyed in London was seven (Heise \& Ellsberg, 1999). There is changing effects to the number of violence because physical injury may no longer mean a direct impact to the lives of women nowadays, but rather some would only consider it as part of their daily lives or behaviour. In general, however, increasing the number of physical injuries increase the rate of violence against women.

Issue 2: Does the reported cases of rape affects the total incidence rate of violence against women?

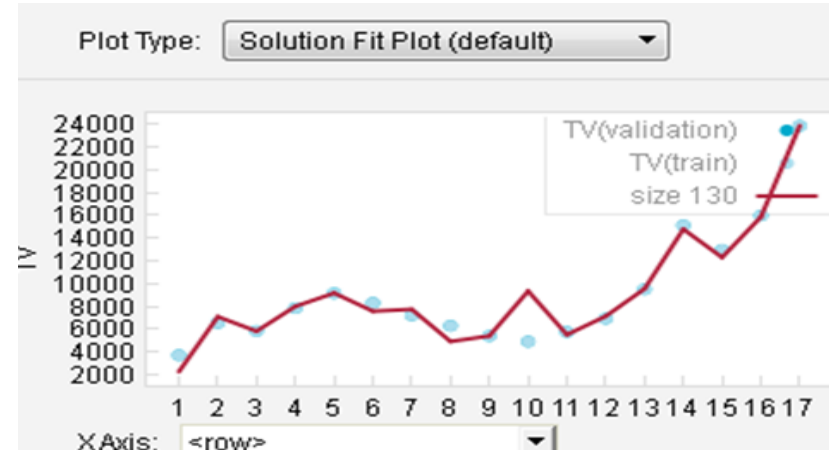

Figure 3: The relationship of rape cases to the total violence rate against woman

$\mathrm{TV}=4.17 \mathrm{e} 3+4.1 \mathrm{RC}+5.69 \mathrm{RC} \cos (2.04 \mathrm{RC})+2.29 \mathrm{RC}$ $\cos (1.04+\mathrm{RC})+6.84 \mathrm{RC} \cos (204 \mathrm{RC})^{2} \cos (5.51 \mathrm{e} 3)$ $\cos (2.04 \mathrm{RC})^{2}$

\begin{tabular}{|c|c|}
\hline Solution & $\begin{array}{l}\text { TV }=4169.30850543551+4.09534369529974^{*} R \\
C+5.68824627454714^{*} R C^{*} \cos (2.04372977259 \\
\left.337^{*} R C\right)+2.29377247343823^{*} R C^{*} \cos (1.04377 \\
00201447+R C)+6.83937222218655^{\star} R C^{*} \cos (2 . \\
\left.04372977259337^{\star} R C\right)^{\wedge} 2^{*} \cos (5508.521977403 \\
\left.16^{*} \cos \left(2.04372977259337^{*} R C\right)^{\wedge} 2\right)\end{array}$ \\
\hline "R^2 Goodness of Fit" & 0.93985346 \\
\hline Correlation Coefficient" & 0.96991925 \\
\hline "Maximum Error" & 4445.3343 \\
\hline "Mean Squared Error" & 1502168.4 \\
\hline "Mean Absolute Error" & 638.39867 \\
\hline Coefficients & 12 \\
\hline Complexity & 130 \\
\hline Primary objective & 638.39867 \\
\hline $\begin{array}{l}\text { "Fit (Normalized Primary } \\
\text { Obj.)" }\end{array}$ & 0.1889773 \\
\hline
\end{tabular}

Solution details (Calculated on validated data)

The relationship of rape cases to the total violence rate against women is shown in figure 2 graph. The data shows a trigonometric fit trend (see equation 2). The R2 is close to 1 indicating a reasonably good model fit and it shows a strong correlation between $\mathrm{x}$ and $\mathrm{y}$ variables. Fluctuations in the graph indicate a nonlinear relationship. Increasing the incidents of rape increases the recorded number of violence against women. The decrease in the trend indicates an inverse relation of the two variables which would mean that rape cases are not 
considered as part of the emerging violence against women. Although both girls and boys can be victims of sexual abuse, most studies report that the prevalence of abuse among girls is at least 1.5 to 3 times that among boys, and sometimes much more. In Barbados, for example, $30 \%$ of women and $2 \%$ of men reported behaviour constituting sexual abuse in childhood or adolescence. Abuse among boys may be underreported compared with abuse among girls, Sexual abuse can lead to a wide variety of unhealthy consequences, including behavioural and psychological problems, sexual dysfunction, relationship problems, low self-esteem, depression, thoughts of suicide, alcohol and substance abuse, and sexual risk-taking. Women who are sexually abused in childhood also are at greater risk of being physically or sexually abused as adults. Although for some children the effects of sexual abuse are severe and long-term, not all will experience consequences that persist into later life. Sexual abuse is most likely to cause long-term harm when it extends over a long period, is by a father or father figure, involves penetration, or involves force or violence (Heise \& Ellsberg, 1999).

Issue 3. Which among the predictors of violence on women greatly affects the total number of VAW?

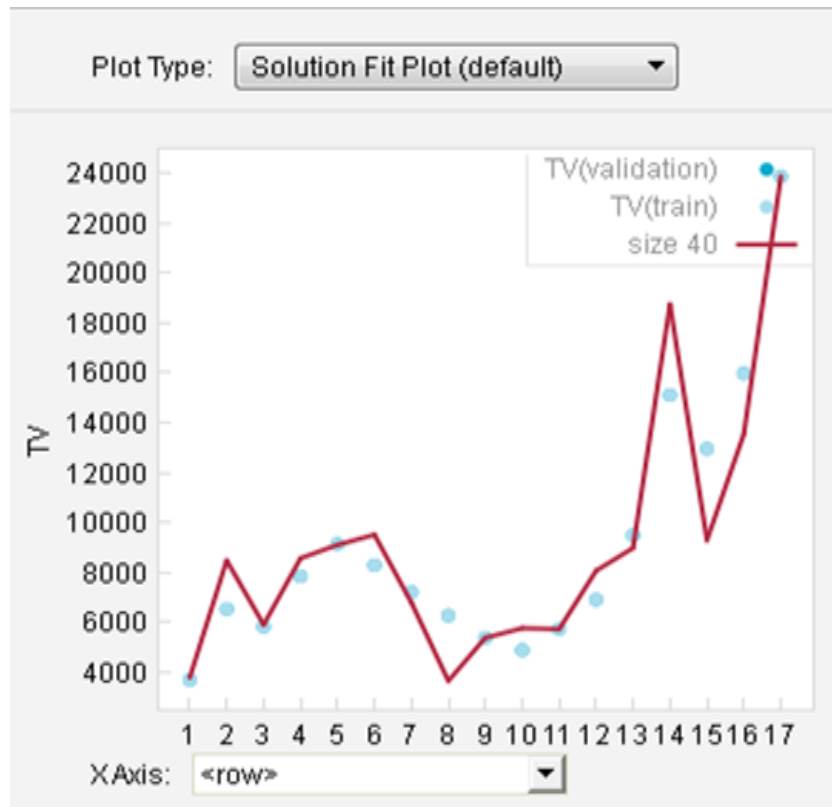

Figure 4: The correlation of physical injury and rape case to the total violence rate against woman

Formula: $\quad \mathrm{TV}=51.7 \mathrm{PI}+0.0812 \mathrm{RC}^{2}+3.83 \mathrm{e} 3 \cos (81.4$ $\mathrm{PI})+5.83 \mathrm{e}-6 \mathrm{RC} \mathrm{PI}^{2}-4.4 \mathrm{e} 4-0.0688 \mathrm{PIRC}-0.00359 \mathrm{PI}^{2}$

\begin{tabular}{|l|l|}
\hline Solution & TV=51.6838296581956*PI+0.081183337930432 \\
& $7^{\star} \mathrm{RC}^{\wedge} 2+3824.9499986371^{*} \cos (81.39189015052$ \\
& $\left.04^{*} \mathrm{PI}\right)+5.83285322803603 \mathrm{e}-6^{*} \mathrm{R} C^{*} \mathrm{P}^{\wedge} 2-$ \\
$44017.51476522180 .0688129722585482^{*} \mathrm{PI}{ }^{*} \mathrm{RC}-$ \\
& $0.00358778130362732^{*} \mathrm{PI}^{\wedge} 2$ \\
\hline "R^2 Goodness of Fit" & 0.88770426 \\
\hline Correlation Coefficient" & 0.94522532 \\
\hline "Maximum Error" & 3654.6272 \\
\hline "Mean Squared Error" & 2804602.5 \\
\hline "Mean Absolute Error" & 1141.842 \\
\hline Coefficients & 8 \\
\hline Complexity & 40 \\
\hline Primary objective & 1141.842 \\
\hline "Fit (Normalized Primary & 0.33800543 \\
\hline Obj.)" & \\
\hline
\end{tabular}

Solution details (Calculated on validated data)

The correlation of physical injury and rape case to the total violence rate against women is shown in graph 3 . The data shows an exponential fit trend (see equation 3 ). The $\mathrm{R}^{2}$ is close to 1 indicating a reasonably good model fit and it shows a strong correlation between $\mathrm{x}$ and $\mathrm{y}$ variables. Both variables, physical injury and rape cases, affects the total number of violence against women. There is a positive and direct relationship among the variables. These two factors are the most common contributors on reason behind the affect the competence of women in the society. Physical injury affects more to the rate of violence against women. According to the result of the study by Fanslow \& Robinson, 2011, out of the 956 women who had experienced physical and/or sexual IPV in their lifetime, half were injured at least once as a result of the violence. The most common injuries were abrasions and bruises; followed by cuts, punctures, bites; and injuries to the eye or ear. Another study claimed that men were more likely to initiate physical contact, use physical force, and inflict injuries than women, although few injuries required medical attention (D. M. Capaldi, 2009).

\section{CONCLUSION AND IMPLICATION}

The increasing prevalence rate of total violence against women is greatly associated with the physical injury and rape cases rate. The Increasing incidents of physical injury does not necessarily relate to a constant increase in the number of violence against women and that is because other women who are victims of these physical injury consider physical abuse as a normal 
occurrence in their daily lives. On the other hand, the incidence of total violence against women also increases due to the increased incidence of rape cases. However there are some instances where rape cases are not taken into account. This decreases the incidence of total violence against women. Denial and fear of social stigma often prevent women from reaching out for help. In surveys, from the study of (Heise \& Ellsberg, 1999) for example, from $22 \%$ to almost $70 \%$ of abused women say that they have never told anyone about their abuse before being asked in the interview those who reach out do so primarily to family members and friends. Few have ever contacted the police. Even so, these two are the most contributing factors that increases rate of incidence of violence against women and physical injury accounts to have affected this growing rate more. The core of violence amongst women is vastly due to gender inequality which acts against women. Countries across the globe, lack data and files on these reported cases but these are still high, and there is a great need to apply research on the different aspects of violence. Future research will help to eradicate this growing number of violence against women both physically or sexually and is highly preventable. Thus, local health services and communities could play a vital and significant role in raising more awareness among the public to prevent the occurrence of untoward violence. Health professionals also play a vital role in giving physical, mental and emotional support to women who are victims of violence. Finally, a strong and committed involvement on governments and the civil society are imposed to end violence in women.

\section{REFERENCES}

Bernarte, R.P., Acedegbega, Q.M., Fadera, M.L. \& Yopyop, H.J. (2018). Violence Against Women in the Philippines. Asia Pacific Journal of Multidisciplinary Research, 6(1), pp 117-124.

D.M. Capaldi, J.W. (2009). Official Incidents of Domestic Violence: Types, Injury, and Associations with Nonofficial Couple Aggression. PMC, 24(4), pp 502-519.

Fanslow, J.L. \& Robinson, E.M. (2011). Physical injuries resulting from intimate partner violence and disclosure to healthcare providers: results from a New Zealand population-based study. Injury Prevention, 17(1), pp 37-42.

Heise, L. \& Ellsberg, M. A. (1999). Ending Violence Against Women. Department of Health. Published by the Population Information Program, Center for Communication Programs, The Johns Hopkins University School of Public Health, USA.

Krantz, G. \& Garcia-Moreno, C. (2005). Violence against Women. Journal of Epidemiology and Community Health, 59(10), pp 818-821.

Philippine Commission on Women (2014). Statistics on violence against Filipino women. Retrieved from: www.pcw.gov.ph

Philippine Commission on Women, National Machinery for Gender Equality and Women's Empowerment (2009). Violence Against Women (VAW). J.P. Laurel St. San Miguel Manila, Philippines.

Sandvik, M., Nesset, M.B., Berg, A. \& Søndenaa, E. (2017). The Voices of Young Sexual Offenders in Norway: A Qualitative Study. Open Journal of Social Sciences, 5, pp 82-95.

World Health Organization (2017). Violence against women. Global Health Observatory (GHO) data. Retrieved from: https://www.who.int/gho/women_and_health/violence/en/ 